\title{
Recombinant human luteinizing hormone supplementation may improve embryo quality in in vitro fertilization/ intracytoplasmic sperm injection cycles with gonadotropin-releasing hormone antagonist protocol
}

\author{
Amir Wiser, Ariel Hourvitz, Yoav Yinon, Jacob Levron, Jehoshua Dor, Shai Elazar Elizur
}

IVF Unit, Division of Obstetrics and Gynecology, Chaim Sheba Medical Center, Tel Hashomer Hospital, Affiliated with the Sackler School of Medicine, Tel Aviv University, Tel Aviv, Israel.

Email: wiserniv@netvision.net.il

Received 18 March 2011; revised 16 April 2011; accepted 25 April 2011.

\begin{abstract}
Objective: To evaluate the effects of recombinant LH (rLH) supplementation on embryo quality in IVF/ICSI cycles with GnRH antagonist. Study design: Prospective, randomized controlled study. Thirty women were enrolled, 15 in the study (FSH + rLH) group and 15 in the control (rFSH only) group. On the day GnRH antagonist was started, the study group patients received $75 \mathrm{IU}$ of $\mathrm{rLH}$ in addition to rFSH. The main outcome measures were embryo quality, number of oocytes retrieved, and fertilization rate. Results: The rLH group had significantly more top-quality embryos (36/43, 84\%) compared to the control group $(40 / 68,59 \%$; $p=$ 0.006). Fertilization rates and number of oocytes retrieved were similar between groups. Progesterone and estradiol $\left(E_{2}\right)$ concentrations in follicular fluid were higher in the study group compared to controls $(16.5 \pm 2.5 \mu \mathrm{g} / \mathrm{ml}$ vs. $11.4 \pm 3.6 \mu \mathrm{g} / \mathrm{ml}$ progesterone, $P=0.07$; and $687 \pm 112 \mathrm{pg} / \mathrm{ml}$ vs. $471 \pm$ $\left.65 \mathrm{pg} / \mathrm{ml} \mathrm{E}_{2}, \mathrm{p}=0.08\right)$. Conclusion: Adding $\mathrm{rLH}$ to ovarian stimulation with GnRH antagonist can yield higher quality embryos.
\end{abstract}

Keywords: Recombinants LH; Antagonist Protocol; Embryo Quality; IVF Treatment

\section{INTRODUCTION}

Despite the vast experience in various in vitro fertilization (IVF) protocols, the beneficial effect of LH supplementation during ovarian stimulation is still far from clear [1]. This controversy is supported by the theory of "LH ceiling levels," a yet-to-be-defined serum LH concentration, above which LH is believed to cause detri- mental effects on oocyte development and implantation [2].

Gonadotropin-releasing hormone (GnRH) antagonists offer the opportunity to control endogenous LH rapidly. $\mathrm{GnRH}$ antagonists act on gonadotroph secretion cells through the immediate, competitive blockade of GnRH receptors and induce a marked decrease in serum $\mathrm{LH}$ levels and a less pronounced decrease in FSH secretion [3]. Data regarding the role of LH activity in GnRH antagonist protocols are scarce and firm conclusions cannot be drawn [4]. The MERIT study [5] has been suggested that supplementation ovarian stimulation with LH during long GnRH agonist protocol has a beneficial effect on embryo quality. However, very few studies reported on recombinant $\mathrm{LH}$ (rLH) addition to GnRh antagonist cycles [6,7]. One study [7] found no evident benefit to rLH supplementation during GnRH antagonist cycle. On the other hand, Acevedo et al. [6] described that $\mathrm{rLH}$ supplementation improved the rate of top quality embryos in recipients whose embryos originate from GnRH- antagonist-treated donors.

Therefore, the aim of this prospective study was to evaluate the effects of rLH supplementation on embryo quality in IVF/ICSI cycles using a GnRH antagonist protocol.

\section{MATERIAL AND METHODS}

A prospective, randomized, controlled study was designed. Inclusion criteria were women with a normal menstrual cycle (25 - 34 days), 20 to 36 years of age, and BMI less than $30 \mathrm{~kg} / \mathrm{m}^{2}$. Exclusion criteria included polycystic ovaries, basal FSH $>10 \mathrm{IU} / \mathrm{Ml}$ and more than five previous IVF failures. The study was approved by the local Institutional Review Board and written informed consent was obtained from each participant after detailed explanation. 
On day three of the menstrual cycle, all patients underwent ultrasound to exclude ovarian cysts and a blood test for serum estradiol $\left(\mathrm{E}_{2}\right)$, progesterone and LH levels. When no ovarian cysts were observed, $\mathrm{E}_{2}$ level was below $40 \mathrm{pg} / \mathrm{ml}$ and progesterone level below $1.0 \mathrm{ng} / \mathrm{ml}$, ovarian stimulation was started. The patients were randomized, during the initial visit in the clinic, to rLH 75 IU supplementation at the day when GnRH antagonist was started (study group) and rFSH only (control group). The two groups started the ovarian stimulation with 150 - 225 IU/day rFSH (Gonal F, Merck, Serono SA, Aubunne, Switzerland) for five days. After five days, the patients underwent ultrasound and blood test for $E_{2}$, progesterone, and LH levels; rFSH dose was adjusted when necessary. When the leading follicle reached 13 $\mathrm{mm}$ in diameter, GnRH antagonist (Cetrotide Merck, Serono SA, Switzerland) was added. Study group patients received 75 IU of rLH (Luveris, Merck, Serono SA, Switzerland) starting the same day as GnRH antagonist, combined with the rFSH dose, whereas those randomized to the control group continued stimulation with rFSH only, during the entire ovarian stimulation period. When at least three leading follicles achieved an $18 \mathrm{~mm}$ diameter, $250 \mathrm{mcg}$ of recombinant hCG (Ovitrel, Merck Serono SA, Bari, Italy) was administered. Ovum pick up was performed 36 hours later. On the day of OPU, four leading follicles were aspirated separately. $E_{2}$, progesterone, FSH, and $\mathrm{LH}$ levels in the follicular fluid were measured after removal of the oocytes. Fertilization was assessed 20 hours after insemination for the appearance of two pronuclei. Embryos were graded from one to four, based on fragmentation rate and the size and number of blastomers: grade 4 embryos were equalsized symmetrical blastomers with no fragmentation; grade 3 were equal-sized symmetrical cells with less than $10 \%$ fragmentation; grade 2 were non-symmetrical blastomers with $10 \%$ - 50\% fragmentation; and grade 1 had more than $50 \%$ fragmentation. Embryos graded 3 and 4 were transferred and the remaining embryos were cryopreserved. Up to three, best-quality embryos were transferred on day two or three, (according to Israeli Fertility Association policy guidelines) and the remaining top-quality embryos were cryopreserved.

The following parameters were compared between the two groups serum $\mathrm{E}_{2}$, progesterone, and LH concentrations (at the time of hCG administration), follicular fluid levels of $\mathrm{E}_{2}$, progesterone, FSH, and LH, the number of retrieved oocytes, fertilization rate, embryo quality, and pregnancy rate. The main outcome measure was embryo quality.

Statistical analysis: The chi-square and Fisher's exact tests were used to compare proportions. Continuous variables (presented as mean and SD) tested by student t-test or ANOVA and p-value of less than 0.05 was con- sidered statistically significant.

\section{RESULTS}

A total of 30 women were enrolled, 15 in the study (rLH) group and 15 in the control group. Two women from the study group were removed from the study due to technical errors in taking their medication. There were no differences between the two groups regarding the number of previous IVF cycles and serum basal FSH and LH levels (Table 1). Although women in the study group were slightly older that those in the control group (32.5 \pm 2.3 years vs. $29.3 \pm 3.6$ years of age, respectively; $p=$ 0.03), this difference does not seem to have any clinical relevance (Table 1). The sperm parameters of women's partners were also similar. Total serum $\mathrm{E}_{2}$ concentration and the serum $E_{2}$ concentration per retrieved oocyte on the day of hCG administration was higher but not significant in the rLH group compared to the control group $(1461.0 \pm 754 \mathrm{pg} / \mathrm{ml}$ vs.1088 $\pm 601 \mathrm{pg} / \mathrm{ml}$; and $250.7 \pm$ $156.0 \mathrm{pg} / \mathrm{ml}$ vs. $161.2 \pm 83.4 \mathrm{pg} / \mathrm{ml}$; , respectively) (Table 2). The serum progesterone levels were not significantly different between groups; $0.9 \pm 0.6 \mathrm{pg} / \mathrm{ml}$ in $\mathrm{rLH}$ group and $0.7 \pm 0.4 \mathrm{pg} / \mathrm{ml}$ in the control group. The total amount of rFSH used during ovarian stimulation, as well as the number of ovarian stimulation days was similar in both groups. In all other cycle characteristics, no significant differences were found between the two groups.

Serum LH levels in both groups decreased significantly from basal levels on day three of the menstrual cycle to the levels on the day of hCG injection. In study group patients, the mean serum LH level decreased from $5.2 \pm 2.2 \mathrm{IU} / \mathrm{ml}$ on cycle day three to $2.9 \pm 1.6 \mathrm{IU} / \mathrm{ml}$ on the first day of GnRH antagonist administration and to $2.4 \pm 1.5 \mathrm{IU} / \mathrm{ml}$ on the day of hCG administration. Patients from the control group also showed reduced serum $\mathrm{LH}$ levels from $4.9 \pm 1.9 \mathrm{IU} / \mathrm{ml}$ on day three to $2.2 \pm 1.2$ $\mathrm{IU} / \mathrm{ml}$ on day of $\mathrm{GnRH}$ antagonist initiation and $1.4 \pm$ $1.0 \mathrm{IU} / \mathrm{ml}$ on day of hCG. However, the decrease in serum LH was not significantly different between the two groups (Figure 1).

Table 1. Patient characteristics.

\begin{tabular}{cccc}
\hline & $\begin{array}{c}\text { Study } \\
\text { group }\end{array}$ & $\begin{array}{c}\text { Control } \\
\text { group }\end{array}$ & P value \\
\hline Age (years) & $32.5 \pm 2.3$ & $29.3 \pm 3.6$ & $\mathbf{0 . 0 3}$ \\
$\begin{array}{c}\text { Primary infertility } \\
\begin{array}{c}\text { Previous IVF cycles } \\
\text { (mean } \pm \text { sd) }\end{array}\end{array}$ & $3.0 \pm 2.4$ & $69.2 \%$ & NS \\
$\begin{array}{c}\text { Basal FSH IU/L } \\
\text { Basal LH IU/L }\end{array}$ & $7.4 \pm 1.8$ & $6.5 \pm 1.9$ & NS \\
\hline
\end{tabular}


Table 2. Cycle characteristics during the IVF treatment.

\begin{tabular}{lccc}
\hline & $\begin{array}{c}\text { Study group } \\
(\mathrm{N}=15)\end{array}$ & $\begin{array}{c}\text { Control group } \\
(\mathrm{N}=13)\end{array}$ & P value \\
\hline Peak E level on hCG (pg/ml) & $1461 \pm 754$ & $1088 \pm 601$ & NS \\
E2 concentration, per retrieved oocyte $(\mathbf{n g} / \mathbf{m l})$ & $250.7 \pm 156.0$ & $161.2 \pm 83.4$ & $\mathbf{0 . 0 8}$ \\
Serum progesterone on hCG $\mathbf{( n g / m l )}$ & $0.9 \pm 0.6$ & $0.7 \pm 0.4$ & NS \\
Endometrial thickness on hCG $(\mathbf{m m})$ & $9.2 \pm 1.7$ & $10.0 \pm 2.0$ & NS \\
rFSH (total IU) & $1800 \pm 784$ & $1960 \pm 445$ & NS \\
Days of stimulation & $9.3 \pm 2.4$ & $9.8 \pm 1.8$ & NS \\
Mean number of retrieved oocytes & $6.3 \pm 1.6$ & $8.3 \pm 6.1$ & NS \\
Rate of ICSI & $48 \%$ & $36.8 \%$ & NS \\
Fertilization rate & $62.0 \%$ & $52.4 \%$ & NS \\
Embryos available for transfer & $(36 / 43) 84 \%$ & $(40 / 68) 59 \%$ & $\mathbf{0 . 0 0 6}$ \\
Mean number of embryos transferred (ET) & $2.1 \pm 0.6$ & $1.9 \pm 0.8$ & NS \\
Percentage of cryopreserved embryos & $(14 / 43) 33 \%$ & $(11 / 68) 16 \%$ & 0.005 \\
\hline
\end{tabular}

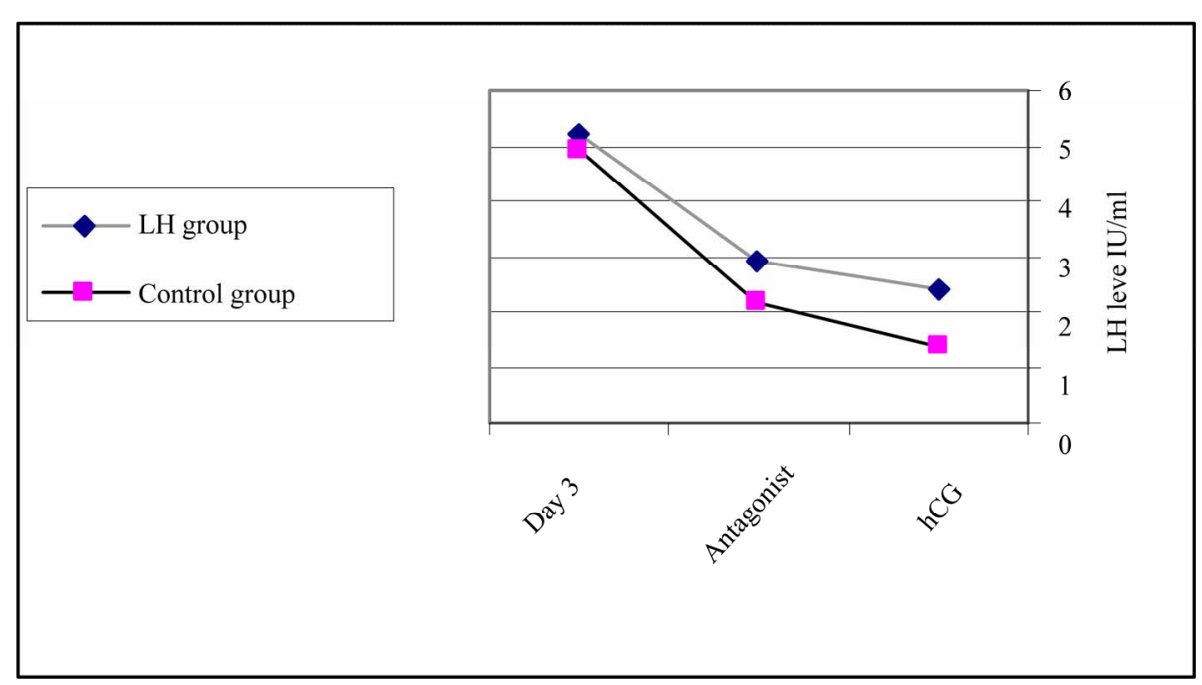

Figure 1. LH level during ovarian stimulation.

The mean number of oocytes retrieved and fertilization rates were not significantly different between the rLH and control groups $(6.3 \pm 1.6$ vs. $8.3 \pm 6.1$ and $62.0 \%$ vs. $54.4 \%$, respectively). The number of embryos transferred (ET) was similar in both groups (mean $2.1 \pm$ 0.6 in the rLH group compared to $1.9 \pm 0.8$ in the Control group). However, the percentage of grade 3-4 top-quality embryos available for transfer, out of all fertilized oocytes was significantly higher, $(36 / 43,84 \%)$ in the rLH group compared to the control group (40/68, $59 \%, \mathrm{p}=0.006)$. Moreover, the percentage of remaining embryos those were suitable for Cryopreservation after embryo transfer, was significantly higher in the $\mathrm{rLH}$ group $(14 / 43,33 \%)$ compared to the control group $(11 / 68,16 \%, \mathrm{p}=0.05$; Table 2).

Hormonal concentrations of FSH and LH in the fol- licular fluid were similar in both groups (Table 3). However, there was a trend towards higher progesterone and $\mathrm{E}_{2}$ concentrations in the follicular fluid in the study group in compared to the control group $(16.5 \pm 2.5$ $\mu \mathrm{g} / \mathrm{ml}$ vs. $11.4 \pm 3.6 \mu \mathrm{g} / \mathrm{ml} ; \mathrm{P}=0.07$ and $687 \pm 112 \mathrm{pg} / \mathrm{m}$ vs. and $471 \pm 65 \mathrm{pg} / \mathrm{ml}, \mathrm{P}=0.08$ ) respectively.

Table 3. Hormone concentrations in follicular fluid.

\begin{tabular}{cccc}
\hline & Study group & Control group value & P \\
\hline FSH (IU/ml) & $3.2 \pm 0.7$ & $3.2 \pm 0.8$ & NS \\
LH (IU/ml) & $4.5 \pm 0.7$ & $4.9 \pm 0.5$ & NS \\
$\begin{array}{c}\text { Progesterone } \\
\text { (nmol/ml) }\end{array}$ & $16.5 \pm 2.5$ & $11.4 \pm 3.6$ & $\mathbf{P}=\mathbf{0 . 0 7}$ \\
$\begin{array}{c}\text { Estradiol level } \\
\text { (pg/ml) }\end{array}$ & $687 \pm 112$ & $471 \pm 65$ & $\mathbf{P}=\mathbf{0 . 0 8}$ \\
\hline
\end{tabular}




\section{DISCUSSIONS}

This study demonstrates that rLH supplementation during GnRH antagonist cycles may improve embryo quality.

It is well established that FSH and LH play separate but complementary roles in folliculogenesis. The "two cell, two gonadotropin theory" suggests that the interaction between FSH and LH is crucial for appropriate folliculogenesis and oocyte maturation. Throughout most of the follicle's development, LH responsiveness is restricted to the thecal cells that are differentiated in the follicular pre-antral stage. During folliculogenesis, androgens are produced in the thecal cells of antral follicles in response to LH stimulation [8]. Androgens have been shown to stimulate early follicular development and reduce the incidence of apoptosis. High androgen concentrations (or high androgen/estrogen ratios) have been observed in lower quality oocytes [9].

Studies comparing rFSH to urinary gonadotropins ( $\mathrm{LH}$ and FSH) in down-regulated cycles with GnRH agonist protocol [10] and mainly in GnRH agonist long protocol [11] have been performed. Nevertheless, very few studies reported on rLH addition in GnRH antagonist cycles [6,7]. One study [7] found no evident benefit to rLH supplementation during GnRH antagonist cycles. However, in that study one injection of long acting 3mg cetrorelix was used. On the other hand, Acevedo et al. [6] described that rLH supplementation improved the number of top quality embryos in recipients whose embryos originated from GnRH antagonist-treated donors. This unique model of donor cycles eliminated the endometrial tissue factor and isolated the effect of LH supplementation on the ovary alone. This finding of a higher rate of top quality embryos in patients who were treated with rLH is also supported by our results. The MERIT study [5] also found that supplementing ovarian stimulation with LH has a beneficial effect on embryo quality; however, in that study a long GnRH agonist protocol was used. Moreover, HMG was used and not recombinant LH and in contrast to our study, it was initiated on the first day of ovarian stimulation.

The mechanism of how LH activity mediates improvements of oocyte and embryo quality parameters in IVF is not fully understood. It is speculated that a set of cumulus genes may determine oocyte maturation, fertilization potential, and embryo quality [12]. Data from sibling human oocytes suggest that embryo quality improves when oocytes are allowed to intercalate with $\mathrm{cu}$ mulus cells, indicating an improvement of cytoplasmatic maturation [13]. Data from a gene expression study provided some molecular evidence for a mediation of cumulus cells in embryonic development [14]. It has been proposed that LH activity might influence the cumulus cells surrounding the oocyte [15], affecting the oocytecumulus interaction, the cytoplasmatic maturation of the oocyte, and the quality of its development. Cumulus cell gene expression may provide a direct assessment of fertility potential and a measure of embryo quality.

Another mechanism for LH activity is related to androgen production. Androgens are produced by the theca cells in response to LH. One study described that elevation of intrafollicular androgen concentration in early follicular phase, resulted in a modest increase in the number of good quality embryos [16]. This mechanism could be, in part, the explanation of our results that demonstrated an increase in the quality of embryos among the LH group.

Previous studies have reported on serum hormonal concentration. Cédrin-Cédrin-Durnerin et al. [7] described higher serum peak $\mathrm{E}_{2}$ level in patients treated in with rLH. Bosch et al. [17] found that purified hMG, resulted in higher serum $\mathrm{E}_{2}$ levels but lower progesterone levels compared to the recombinant FSH group. In our patients, the serum $\mathrm{E}_{2}$ level showed a trend toward being higher in the rLH group: no difference was found in progesterone levels between the groups. The difference in the results regarding progesterone levels between our study and that of Bosch, et al. [17] could be due to the different protocols used. Bosch et al. started with HMG from the first day of ovarian stimulation but in our study, rLH was added the day GnRH was administered.

Our study offered the opportunity to correlate follicular fluid hormone concentrations and embryo quality. We have shown that in antagonist cycles, LH supplementation led to increased follicular fluid levels in both $E_{2}$ and progesterone. This is not in agreement with the findings of Smitz et al., [18] who reported an increased follicular level of $E_{2}$ but decreased level of progesterone in hMG compared to rFSH. However, in that study a long GnRH agonist protocol was used and that may explain the different results. It has been shown that $E_{2}$ plays an important role in ovarian cell differentiation [19] and oocyte maturation [19]. Adding recombinant LH in a GnRHantagonist cycle provides sufficient substance products to sustain the synthesis of $E_{2}$, which is necessary for oocyte maturation and differentiation [17].

Serum progesterone level was also found to be a prognostic factor in IVF cycles. Niu et al. [20] reported that women with a high serum progesterone concentration on the day of ovum pick up had a greater number of viable embryos. In our study, follicular fluid levels of both progesterone and $\mathrm{E}_{2}$ were higher in the rLH group. This may partially explain the higher rates of top-quality embryos derived from the LH group.

In conclusion, our study suggests that rLH supplementation on the day of GnRH-antagonist initiation can yield a higher number of top-quality embryos. Addi- 
tional, larger studies are needed to determine the effect on pregnancy and delivery rates.

\section{REFERENCES}

[1] Weghofer, A., Munné, S., Brannath, W., Chen, S., Tomkin, G., Cekleniak, N., et al. (2008) The impact of LH-containing gonadotropins on diploidy rates in preimplantation embryos: Long protocol stimulation. Human Reproduction, 23, 499-503. doi:10.1093/humrep/dem412

[2] Manna, C., Rahman, A., Sbracia, M., Pappalardo, S., Mohamed, E.I., Linder, R., et al. (2005) Serum luteinizing hormone, follicle-stimulating hormone and oestradiol pattern in women undergoing pituitary suppression with different gonadotrophin-releasing hormone analogue protocols for assisted reproduction. Gynecological Endocrinology, 20, 188-194. doi:10.1080/09513590400027141

[3] Albano, C., Smitz, J., Camus, M., Riethmüller-Winzen H, Van Steirteghem A and Devroey P. (1997) Comparison of different doses of gonadotropin-releasing hormone antagonist Cetrorelix during controlled ovarian hyperstimulation. Fertility and Sterility, 6, 917-922. doi:10.1016/S0015-0282(97)81407-0

[4] Kolibianakis, E.M., Venetis, C.A. and Tarlatzis, B.C. (2009) Role of the endocrine profile for the achievement of pregnancy with IVF. Reproductive BioMedicine Online, 18, 37-43. doi:10.1016/S1472-6483(10)60447-6

[5] Ziebe, S., Lundin, K., Janssens, R., Helmgaard, L. and Arce, J.C. (2007) MERIT (Menotrophin vs Recombinant FSH in vitro Fertilisation Trial) Group. Influence of ovarian stimulation with HP-hMG or recombinant FSH on embryo quality parameters in patients undergoing IVF. Human Reproduction, 22, 2404-2413. doi:10.1093/humrep/dem221

[6] Acevedo, B., Sanchez, M., Gomez, J.L., Cuadros, J., Ricciarelli, E. and Hernández, E.R. (2004) Luteinizing hormone supplementation increases pregnancy rates in gonadotropin-releasing hormone antagonist donor cycles. Fertility and Sterility, 82, 343-347.

doi:10.1016/i.fertnstert.2004.03.020

[7] Cédrin-Durnerin, I., Grange-Dujardin, D., Laffy, A., Parneix, I., Massin, N., Galey, J., et al. (2004) Recombinant human LH supplementation during GnRH antagonist administration in IVF/ICSI cycles: A prospective randomized study. Human Reproduction, 19, 1979-1984. doi:10.1093/humrep/deh369

[8] Durnerin, C.I., Erb, K., Fleming, R., Hillier, H., Hillier, S.G., Howles, C.M., et al. (2008) Luveris Pretreatment Group. Effects of recombinant LH treatment on folliculogenesis and responsiveness to FSH stimulation. Human Reproduction, 23, 421-426. doi:10.1093/humrep/dem388

[9] McNatty, K.P., Smith, D.M., Makris, A., Osathanondh, R. and Ryan, K.J. (1979) The microenvironment of the human antral follicle: Interrelationships among the steroid levels in antral fluid, the population of granulosa cells, and the status of the oocyte in vivo and in vitro. The Journal of Clinical Endocrinology \& Metabolism, 49, 851-860. doi:10.1210/jcem-49-6-851

[10] Hompes, P.G., Broekmans, F.J., Hoozemans, D.A. and
Schats. R. (2008) FIRM group. Effectiveness of highly purified human menopausal gonadotropin vs. recombinant follicle-stimulating hormone in first-cycle in vitro fertilization-intracytoplasmic sperm injection patients. Fertility and Sterility, 89, 1685-1693. doi:10.1016/j.fertnstert.2007.05.039

[11] Andersen, A.N., Devroey, P. and Arce, J.C. (2006) Clinical outcome following stimulation with highly purified hMG or recombinant FSH in patients undergoing IVF: A randomized assessor-blind controlled trial. Human Reproduction, 21, 3217-3227. doi:10.1093/humrep/del284

[12] McKenzie, L.J., Pangas, S.A., Carson, S.A., Kovanci, E., Cisneros, P., Buster, J.E., Amato, P. and Matzuk, M.M. (2004) Human cumulus granulosa cell gene expression: A predictor of fertilization and embryo selection in women undergoing IVF. Human Reproduction, 19, 2869 2874. doi:10.1093/humrep/deh535

[13] Hassan, H.A. (2001) Cumulus cell contribution to cytoplasmic maturation and oocyte developmental competence in vitro. Journal of Assisted Reproduction and Genetics, 18, 539-543.

[14] Assou, S., Anahory, T., Pantesco, V., Le Carrour, T., Pellestor, F., Klein, B., et al. (2006) The human cumulus-Oocyte complex gene-expression profile. Human Reproduction, 21, 1705-1719. doi:10.1093/humrep/del065

[15] Platteau, P., Smitz, J., Albano, C., Sørensen, P., Arce, J.C. and Devroey, P. (2004) Exogenous luteinizing hormone activity may influence the treatment outcome in in vitro fertilization but not in intracytoplasmic sperm injection cycles. Fertility and Sterility, 81, 1401-1404. doi:10.1016/j.fertnstert.2003.09.077

[16] Lossl, K., Andersen, A.N., Loft, A., Freiesleben, N.L., Bangsbøll, S. and Andersen, C.Y. (2006) Androgen priming using aromatase inhibitor and hCG during earlyfollicular-phase GnRH antagonist down-regulation in modified antagonist protocols. Human Reproduction, 21, 2593-2600. doi:10.1093/humrep/del221

[17] Bosch, E., Vidal, C., Labarta, E., Simon, C., Remohi, J. and Pellicer, A. (2008) Highly purified hMG versus recombinant FSH in ovarian hyperstimulation with GnRH antagonists-A randomized study. Human Reproduction, 23, 2346-2351. doi:10.1093/humrep/den220

[18] MERIT* Group. (2007) Endocrine profile in serum and follicular fluid differs after ovarian stimulation with HP-hMG or recombinant FSH in IVF patients. Human Reproduction, 22, 676-687.

[19] Couse, J.F., Hewitt, S.C., Bunch, D.O., Sar, M., Walker, V.R., Davis, B.J., et al. (1999) Postnatal sex reversal of the ovaries in mice lacking estrogen receptors alpha and beta. Science, 17, 2328-2331.

[20] Niu, Z., Feng, Y., Zhang, A., Sun, Y. and Zhang, H. (2008) Progesterone levels on oocyte retrieval day can predict the quantity of viable embryos but not pregnancy outcome of intracytoplasmic sperm injection. Gynecological Endocrinology, 24, 452-458. doi:10.1080/09513590802196247 